\title{
Effects of prefeeding in a fixed-interval reinforcement schedule'
}

\author{
RICHARD L. SHULL AND AARON J. BROWNSTEIN \\ DEPARTMENT OF PSYCHOLOGY, ARIZONA STATE \\ UNIVERSITY, Tempe, Ariz. 85281
}

When a pigeon trained on a fixed-interval 1 min reinforcement schedule was prefed $20 \mathrm{~g}$ of mixed grain prior to his daily session, his response rate was much lower than when he was not prefed. An index of the temporal distribution of responses within the interval, the quarter-life, was moderately related to deprivation level.

The performance generated by a fixed-interval (FI) schedule of reinforcement can be characterized by two different types of calculations: (1) by a measure of the overall response rate (responses per time) and (2) by a description of the temporal distribution of responses in time within an FI. Several writers have proposed methods for describing the temporal distribution of responses with a single quantitative index. One such index, the quarter-life $(\mathrm{Q})$. is the time in the FI (or the proportion of time in the FI) for the emission of one-fourth of the responses made during the interval (Herrnstein \& Morse, 1957: Gollub, 1964). Gollub (1964) reported that response rates and Qs were essentially uncorrelated when rats and pigeons were maintained at a constant deprivation level.

However, when deprivation level is varied, the two measures of FI performance may not be independent. Weiss \& Moore (1956) trained two groups of rats on an FI-3 min schedule. One group was $22 \mathrm{~h}$ deprived and the other group was $5 \mathrm{~h}$ deprived. For data analysis the FI-3 was divided into 10 equal subintervals and the number of responses made in each subinterval was counted separately. Weiss and Moore reported that the number of responses made in each subinterval was greater for the $22-\mathrm{h}$ deprived group than for the 5 -h deprived group. Also, the two functions relating number of responses and the ordinal position of the subinterval were parallel, linearly increasing functions. Using the two linear equations provided by Weiss and Moore, we computed the mean number of responses per FI-3 and the $Q$ for each deprivation group. For the 22-h deprived group the $Q$ was .326 and for the 5-h deprived group the $Q$ was .425 . The mean number of responses per FI-3 were 73.0 and 32.6 for the $22-\mathrm{h}$ and 5 -h deprived groups, respectively.

The present experiment was undertaken to further investigate the effects of deprivation level on response rate and $Q$ with a pigeon exposed to an FI-1 min schedule of reinforcement. In this study the amount of exposure to the FI schedule was considerably greater than in the Weiss and Moore study. In the latter study the rats were exposed to the FI-3 min schedule for a total of $400 \mathrm{~min}$ whereas in the present study the pigeon was exposed to the Fl-1 $\min$ for $112 \mathrm{~h}$.

Subjects and Apparatus. The $\mathrm{S}$ was one Silver King pigeon with some previous experimental history. He was reduced to $80 \%$ of his free-feeding weight at the start of the experiment.

The experimental chamber, enclosed in a sound-attenuated ice chest, contained a mechanism for delivering mixed grain and a translucent key that could be transilluminated from behind. Pecks on the key exceeding $20 \mathrm{~g}$ force operated control and recording circuitry and also operated a "feedback" relay mounted in the chamber. The recording circuits were programmed so that the FI-1 min schedule was divided into five 12-sec subintervals. Responses made during each 12-sec subinterval were accumulated throughout a session on five separate counters. Responses made during the first interval in the session were not recorded.

A reinforcement period consisted of $3 \mathrm{sec}$ access to mixed grain during which time the key was darkened and the feeder was illuminated. Sessions were terminated automatically following the 61 st reinforcement.

Procedure. For all conditions of the experiment the schedule was FI-1 $\min$. Sessions were begun at approximately the same time each day: $0-\mathrm{g}$ prefeeding Condition-The $S$ received mixed grain only during his experimental session; 10-g prefeeding Condition-A cup containing $10 \mathrm{~g}$ of mixed grain was placed in the S's home cage during the $1 \mathrm{~h}$ prior to his daily session 20-g prefeeding Condition-A cup containing $20 \mathrm{~g}$ of mixed grain was placed in the S's home cage during the $1 \mathrm{~h}$ prior to his daily session. Occasionally a few grains remained in the cup at the end of the hour.

These three prefeeding conditions were alternated in the following sequence. The number of sessions devoted to each condition are shown in parentheses: $0-\mathrm{g}$ prefeeding (30), 10-g prefeeding (5), 20-g prefeeding (14), $0-\mathrm{g}$ prefeeding (26), 20-g prefeeding (22), 0 -g prefeeding (10).

Results and Discussion. The total number of responses recorded during the session was divided by the number of intervals in the session during which responses were recorded (i.e., by 60 ). Response rates for the last five sessions of the initial 0-g prefeeding Condition and for all following sessions are shown in the top panel of Fig. 1. Response rates obtained during the 10 -g prefeeding Condition were somewhat higher than response rates obtained during the initial $0-\mathrm{g}$ prefecting Condition. The last two $0-4$ prefeeding Conditions produced the highest response rates and the two 20-g prefeeding Conditions produced the lowest response rates.

The proportion of the Fl-1 taken for the emissions of one-fourth of the responses in the FI, the Q. was determined by interpolating between adjacent points on the cumulative response curve obtained by summing the number of responses made in successive 12-sec subintervals. Qs for the last five sessions of the initial 0-g prefeeding Condition and for all following sessions are shown in the middle panel of Fig. 1. Highest Qs were produced by the second and third $0-\mathrm{g}$ prefeeding Conditions. Lowest Qs occurred during the $20-\mathrm{g}$ prefeeding Conditions. The magnitude of the difference in Qs between prefeeding conditions was small.

The weight of the $S$ varied with the amount of prefeeding. The bottom panel of Fig. 1 shows the weight of the $S$ during the last five sessions of the initial 0 -g prefeeding Condition and for all following sessions.

In the study by Weiss and Moore and in the present study response rates produced by the higher deprivation condition were more than double the response rates produced by the lower deprivation condition. However, with respect to the effect of deprivation level on $Q$, the results of the two studies differed. In the earlier study an inverse relation was found between hours of

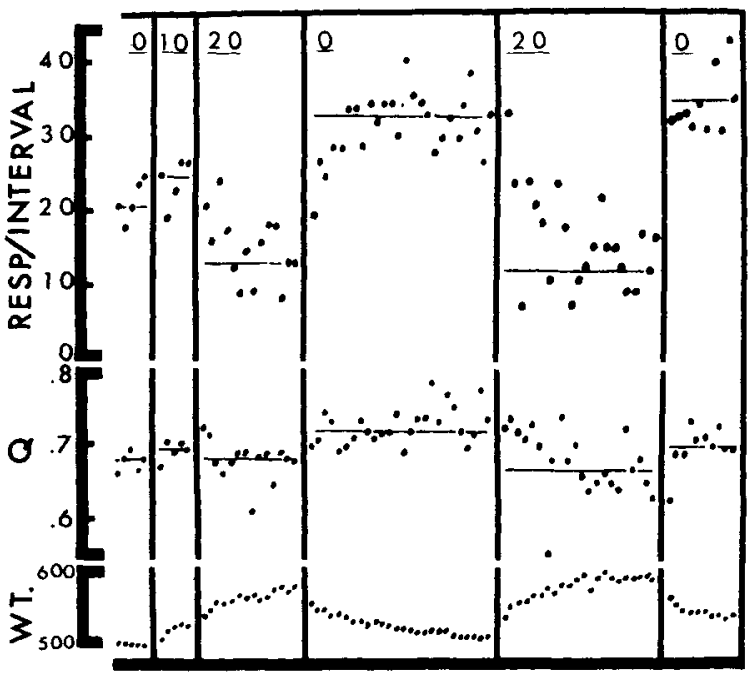

SESSIONS

Fig. 1. Responses per interval (top panel), quarter-life (middle panel), and body weight in grams (bottom panel) are shown for each session after the $25 \mathrm{th}$. The amount (grams) of mixed grain given to the pigeon before a session is shown in the upper margin. Horizontal lines indicate medians based on the last five sessions devoted to a prefeeding condition. 
deprivation ( $5 \mathrm{~h}$ and $22 \mathrm{~h}$ ) and $\mathrm{Q}(.425$ and .326$)$. In the present study a small positive relation was found between the amount of deprivation (20 $\mathrm{g}$ and $0 \mathrm{~g}$ prefeeding) and $\mathrm{Q}(.665$ and .710medians for the last two conditions).

The factors responsible for these discrepancies cannot be determined because of numerous procedural differences. However, the fairly low values of $Q$ computed from Weiss and Moore's data suggest that their training period may not have been of sufficient duration to produce a terminal level of performance. The $Q$ values for rats given extensive training on FI schedules of 2 to $4 \mathrm{~min}$ duration have been reported to be greater than .6 (Gollub, 1964; Sherman, 1959). Perhaps the effect of deprivation level on $Q$ depends upon whether the performance is transitional or terminal.

\section{REFERENCES}

GOLLUB, L. The relations among measures of performance on fixed interval schedules. J. exp. Anal. Behav., 1964, 7, 237-243.

HERRNSTEIN, R. S., \& MORSE, W. H. Effects of pentobarbitol on intermittently reinforced behavior. Science, 1957, 125, 929-931.

SHERMAN, J. G. The temporal distribution of responses on fixed interval schedules. Unpublished doctoral dissertation, Columbia Univ., 1959.

WEISS, B., \& MOORE, E. W. Drive level as a factor in distribution of responses in fixed-interval reinforcement. J. exp. Psychol., 1956, 52, 82-84.

NOTE

1. This research was supported by Grant No. MH-11917 from the Public Health (NIMH) Service to Arizona State University. 